\title{
Characteristics of Extracellular Vesicles in Red Blood Concentrates Change with Storage Time and Blood Manufacturing Method
}

\author{
Ruqayyah J. Almizraq ${ }^{a}$ Jelena L. Holovati ${ }^{a, b}$ Jason P. Acker ${ }^{a, b}$ \\ a Laboratory Medicine and Pathology, University of Alberta, Edmonton, AB, Canada; \\ ${ }^{b}$ Centre for Innovation, Canadian Blood Services, Edmonton, AB, Canada
}

\section{Keywords}

Microvesicles · Microparticles · Red blood cells . In vitro quality . Storage lesion - Blood processing . Red cell filtered . Whole blood filtered

\section{Summary}

Background: Extracellular vesicles (EVs) in blood products are potential effectors of inflammation and coagulation after transfusion. The aim of this study was to assess the impact of different blood manufacturing methods and duration of hypothermic storage on the EV subpopulations in relation to other in vitro quality parameters of red blood cell concentrate (RCC) products. Methods: RCCs were produced using whole blood filtration (WBF) or red cell filtration (RCF) ( $n=12 /$ method), refrigerated for 43 days, and evaluated for EV size profile and concentration, red cell deformability, ATP and 2,3DPG, hemolysis, and hematological indices. Results: The total number of EVs increased significantly with storage in both methods, and WBF-RCCs contained the higher numbers of EVs compared to RCF-RCCs. The concentration of small EVs was greater in WBF-RCCs versus RCFRCCs, with difference between the two methods observed on day 43 of storage $(p=0.001)$. Throughout storage, significant decreases were identified in ATP, 2,3DPG, and $\mathrm{EI}_{\max }$, while an increase in hemolysis was observed in both RCC products. Conclusion: The dynamic shift in the size and concentration of the EV subpopulations is dependent on the blood manufacturing method and length of storage. Better understanding of the potential clinical implications of these heterogeneous populations of EVs are needed.

(c) 2018 S. Karger GmbH, Freiburg

\section{Introduction}

Red blood cell concentrates (RCCs) are used frequently as a transfusion therapy product worldwide $[1,2]$. The quality assurance of the blood components is vital during processing and storage for the patient safety [3]. Although several accomplishments have been made to maintain the integrity and function of blood cells and to improve the quality of stored blood components for better transfusion outcomes [4-8], a number of studies have revealed that transfusion of red blood cell $(\mathrm{RBC})$ products is still associated with increased risk of adverse clinical events [9-15]. Many recent studies have focused on effects of storage duration on the quality of blood products and their clinical consequences $[10,11$, $13,16,17]$. However, the quality of the RCC products can depend on several other factors such as donor-to-donor variability, variation in the quality testing methods, and blood manufacturing methods $[1,2,18,19]$. Although the processing of the blood components is controlled [3], the RCCs issued for transfusion are not manufactured or treated equally, and the variations between RCCs produced by different manufacturing methods are not well appreciated. In Canada, the blood processing methods include red cellfiltered (RCF, top-and-bottom) and whole blood-filtered (WBF, top-and-top) RCCs [18]. Variations between differently manufactured RCCs have been observed in many studies, such as differences in levels of hemoglobin, hematocrit and cytokines, all of which have been shown to influence the quality profiles of the transfused products [6, 20-22].

Extracellular vesicles (EVs) vary in RCCs and plasma components depending on the blood processing method used [22-25]. Blood products can contain a mixed population of EVs, including exosomes and microvesicles, which are heterogeneous submicronsized vesicles surrounded by a phospholipid bilayer containing proteins, lipid, and a variety of RNA molecules [26-30]. The pres-

\section{KARGER}

() 2018 S. Karger GmbH, Freiburg 
ence of EVs in stored RCC products, which accumulate during storage, has been identified as a significant indicator of storage lesion $[4,5,31,32]$. Based on the current knowledge, it has been suggested that EVs in stored blood are associated with a number of adverse outcomes such as neutrophil activation and promoting an inflammatory response in the recipients of older blood [33-36]. Thus, EVs are potentially important in the quality of the blood products, in vitro and in vivo, and clearly require further investigations. Noteworthy, the heterogeneity of EVs with respect to size, concentration, content, and phenotype is not well-considered in most of the studies investigating EVs in RCC products. These characteristics of EVs, particularly those of the small EVs/exosomes (50-200 $\mathrm{nm}$ in size), in stored blood components are not often reported due to the technical challenges in detecting these heterogeneous submicron-sized particles [37]. Although the flow cytometer is the most common technique used to identify and quantify EVs in suspension $[29,38,39]$, EVs less than $300 \mathrm{~nm}$ are undetectable by this method $[28,29,38]$. Accurately distinguishing between diverse subpopulations of EVs in different manufactured RCCs is not usually considered in RBC storage studies. The aim of this study was to assess the impact of different blood manufacturing methods and duration of hypothermic storage on the subpopulations of EVs in relation to other commonly evaluated in vitro quality parameters of RCC products.

\section{Material and Methods}

\section{Blood Collection and Sampling}

Whole blood was collected and RCCs were produced according to standard operating procedures at Canadian Blood Services (CBS). Briefly, whole blood units $(\mathrm{n}=24)$ were collected from eligible donors and manufactured by using either a red cell filtration (RCF; top/bottom, $n=12$ ) or a whole blood filtration (WBF; top/top, $\mathrm{n}=12$ ) as previously explained [22, 40].

During the RCF procedure, whole blood was collected with $70 \mathrm{ml}$ of citratephosphate-dextrose (CPD) anticoagulant and units were rapidly cooled to $18-24^{\circ} \mathrm{C}$ and held overnight. Products were then centrifuged at $3,493 \times g$ for 11 min to separate the blood components (plasma, RBCs, and buffy coat) and saline-adenine-glucose-mannitol (SAGM) was added to the extracted RCCs. The RCC units were leukoreduced by filtration at room temperature within $24 \mathrm{~h}$ of stop-bleed time. For the WBF method, whole blood was collected with $70 \mathrm{ml}$ of $\mathrm{CPD}$ anticoagulant, cooled $\left(1-6^{\circ} \mathrm{C}\right)$ and leukoreduced by filtration within $48 \mathrm{~h}$ of stop-bleed time before being separated. Filtered units were then centrifuged at $4,552 \times g$ for 6 min to separate the blood components (plasma and RBCs only). An automated extractor (Compomat G4) was used to extract plasma, and then SAGM was added to RCCs. All RCC units produced with both manufacturing methods were stored at $1-6{ }^{\circ} \mathrm{C}$ for up to 43 days.

RCC sampling was performed three times during the storage using a validated technique as previously described $[6,41]$. At each testing point (day 7, 21, and 42 ), $14 \mathrm{ml}$ of RBCs was aseptically drawn from each bag into $15 \mathrm{ml}$ conical tubes. For each sample, $10 \mathrm{ml}$ was centrifuged at $2,200 \times g$ for $10 \mathrm{~min}$ at $4{ }^{\circ} \mathrm{C}$ (Eppendorf 5810R; Eppendorf, Mississauga, ON, Canada), and the supernatant was collected for analysis using the tunable resistive pulse sensing (TRPS) technology (qNano system; IZON Science Ltd, Christchurch, New Zealand). The remaining $4 \mathrm{ml}$ of RBCs was used for in vitro quality assessments (hemolysis, spun hematocrit, deformability, ATP, 2,3-DPG, RBC hematologic indices, and flow cytometry).

\section{In vitro Assessment of RCC Units}

Hemolysis was determined using a Drabkin's-based spectrophotometric method as previously described $[6,31,42]$. Briefly, for hematocrit (Hct), RCCs were aspirated into self-sealing Hct capillary tube and read visually after centrifugation for $5 \mathrm{~min}$ in a Hct centrifuge (Hettich Haematokrit Centrifuge Type 2010; Hettich, Tuttlingen, Germany). Total hemoglobin (THb) and supernatant hemoglobin $(\mathrm{SHb})$ was treated with Drabkin's reagent and measured spectrophotometrically using a microplate reader (SpectraMax 384 Plus; Molecular Devices Corp., Sunnyvale, CA, USA). Percent hemolysis was then determined using Hct and measured values for $\mathrm{SHb}$ and $\mathrm{THb}$ as previously described [43].

RBC deformability was measured using a laser-assisted optical rotational cell analyzer (Mechatronics, Zwaage, Netherlands) as previously described [44, 45]. Hematological indices, including RBC count, the mean corpuscular volume (MCV), mean corpuscular $\mathrm{Hb}(\mathrm{MCH})$, mean corpuscular $\mathrm{Hb}$ concentration (MCHC), Hb, and Hct, were determined using a hematological analyzer (Coulter Automated Cell Counter; Coulter AcT, Beckman Coulter, New York, NY, USA) [31, 45]. Adenosine triphosphate (ATP) concentration of RCC samples was assessed spectrophotometrically using a commercially available kit and controls (DiaSys Diagnostic Systems GmbH, Holzheim, Germany), as previously described $[6,31,45]$. The amount of ATP in the sample, calculated as $\mu \mathrm{mol} / \mathrm{dl}$, was normalized using the total $\mathrm{Hb}$ concentration $(\mu \mathrm{mol} / \mathrm{g} \mathrm{Hb})$. Determination of 2,3-diphosphoglycerate (2,3-DPG) was performed using a commercial kit (Roche, Mannheim, Germany) and normalized using the total $\mathrm{Hb}$ concentration as previously described [6].

All in vitro quality parameters were assessed on day 7 (fresh) and day 42 (expiry). The microparticle count by flow cytometry was measured on day 7, 21, 42. The EV size and concentration measured by TRPS were completed on day 8 , 22 , and 43 .

\section{EV Characterization}

Flow Cytometry Assay for EV Quantification

The RBC microparticles (RMPs) count was measured based on a flow cytometry flow rate technique as previously published [31,37] with some modifications. Two markers were used in this study: fluorescein isothiocyanate (FITC) anti-human CD235a antibody (MHGLA01; Invitrogen, Life Technologies, ON, Canada) which was used as a marker for RBCs and RMPs, and APC Annexin V (BD PharMingen, San Jose, CA, USA) which was used to measure the exposure of phosphatidylserine (PS) on the particles. RBCs $(5 \mu \mathrm{l})$ were diluted with $1 \times$ PBS then incubated with FITC anti-human CD235a antibody and APC annexin $\mathrm{V}$ for $15 \mathrm{~min}$ in the dark at room temperature. Prepared samples were run on a bench-top digital flow cytometer (LSR-Fortessa X-20; BD Biosciences, San Jose, CA, USA) and analyzed using BD FACSDiva 8.0.1 software (BD Biosciences). Latex beads $1.0 \mu \mathrm{m}$ in diameter (Bangs Laboratories, Fishers, IN, USA) were used to generate a gate around RMPs to further classify them based on their size (only RMPs $\leq 1.0 \mu \mathrm{m}$ in diameter were analyzed). Frozen RBCs $\left(-80^{\circ} \mathrm{C}\right)$ served as positive controls for RBC microvesiculation. Buffer $(1 \times$ PBS) with FITC antihuman CD235a and APC Annexin V but no RBCs or supernatant was used as a negative control. For nonspecific antibody binding, commercial isotype control against glycophorin A (FITC mouse IgG1, k isotype control; Invitrogen, Life Technologies ) was used. TruCOUNT beads (BD Biosciences) were used to determine the absolute number of RMPs/ $\mu$ l.

TRPS Assay for EV Concentration and Size-Profiling

Quantification and size characterization of EVs in RCCs were measured using a tunable resistive pulse sensing instrument (qNano system; IZON Science Ltd) as previously described [37]. Two different nanopores (NP200 and NP400; IZON Science Ltd) were used in this study to target EVs $<1 \mu \mathrm{m}$ in size using a standard stretch range (43-47 $\mathrm{mm}$ ). Carboxylate polystyrene calibration particles (CPC200/SKP 400; IZON Science Ltd) were used with the NP200 to characterized EVs less than $200 \mathrm{~nm}$ in diameter, while CPC 500 (IZON Science Ltd.) were used with NP400 nanopore to calibrate for EVs $\geq 200 \mathrm{~nm}$. Both 
CPC200 and CPC400 were suspended in Solution A (Fluid Cell Electrolyte, IZON Reagent kit, RK1; IZON Science Ltd) according to the target particle concentration as recommended by the manufacture $\left(1 \times 10^{9}\right.$ particles $/ \mathrm{ml}$ and $5 \times$ $10^{8}$ particles $/ \mathrm{ml}$ respectively). Supernatant samples were diluted with Solution Q (qEV Electrolyte;IZON Science Ltd), and the sample dilution was adjusted as required to target a particle rate of $1,000-2,000 / \mathrm{min}$. Samples were filtered with a $0.80 \mu \mathrm{m}$ Millex syringe filter (SLAA033; Merck Millipore Ltd, Darmstadt, Germany) and/or $0.45 \mu \mathrm{m}$ Millex syringe filter (SLHV033; Merck Millipore Ltd) before being analyzed with NP400 or NP200. Samples and calibration particles measurements were run under the same conditions, and at least 1,000 particles were recorded with two different standard pressure ranges ( 1 unit $=1$ mbar). Data obtained were analyzed using Izon Control Suite software (Izon Control Suite Version 3.2.2.268; Izon Science Ltd). The data sets were filtered to analyze specific populations in each measurement. Samples measured with NP200 were filtered to collect and display the values of particles less than 200 $\mathrm{nm}$ in diameter. Samples measured with NP400 were filtered to display the values of particles from $200 \mathrm{~nm}$ to $1,000 \mathrm{~nm}$.

\section{Statistical Analysis}

Statistical analysis was completed using computer software (IBM SPSS Statistics 23.0, Armonk, NY, USA). Analysis of variance (ANOVA) followed by a Tukey post hoc test was used to identify significant differences within the storage period for EV assays and to evaluate any significance amongst pairwise comparisons of testing time points during the storage time. Using univariate ANOVA followed by Bonferroni test, interaction between the blood manufacturing methods and storage time was examined to determine if manufacturing method type effect varies with storage time. Paired t-tests were used to identify significant differences between the testing time points (days 7 and 42) for the in vitro quality parameters. Correlational analysis was performed using SigmaPlot 13.0 (Systat Software Inc., San Jose, CA, USA). Probability (p) values less than 0.05 were considered significant.

\section{Results}

Flow Cytometer: RMPs and PS Expression Change with Storage Duration and Blood Manufacturing Methods

Flow cytometric analysis showed that the absolute number of CD235+ microparticles/ $\mu$ l gradually increased throughout the storage period for both blood processing methods, RCF and WBF (fig. 1A). In both blood manufacturing methods, a significant increase in the number of RMPs/ $\mu$ l was observed on day 21 (RCF; $\mathrm{p}=0.003, \mathrm{WBF} ; \mathrm{p}=0.017)$ and day $42(\mathrm{RCF}$ and WBF; $\mathrm{p}<0.001)$ of hypothermic storage in comparison to day 7. Early in storage (day 7), a significant difference in the number of RMPs/ $\mu$ l between the RCF and WBF methods was seen $(\mathrm{p}=0.033)$. Further flow cytometric investigation revealed differences between the RCF and WBF methods in the percentage of RMPs expressing PS on day 7 $(\mathrm{p}<0.001)$ and day $42(\mathrm{p}=0.010)$. While there was no significant change in the percentage of RMPs expressing PS observed during storage with RCF-RCCs, a significant decrease in the percentage of RMP expressing PS was detected on day 21 and day $42(\mathrm{p}<0.001)$ with WBF-RCCs. Further analysis of RMPs showed significant decreases in the median fluorescence intensities (MFIs) for the expression of PS on RMPs on day 42 of storage (fig. 1C) for both blood manufacturing products (RCF; $\mathrm{p}=0.035$, WBF; $\mathrm{p}<0.001$ ).
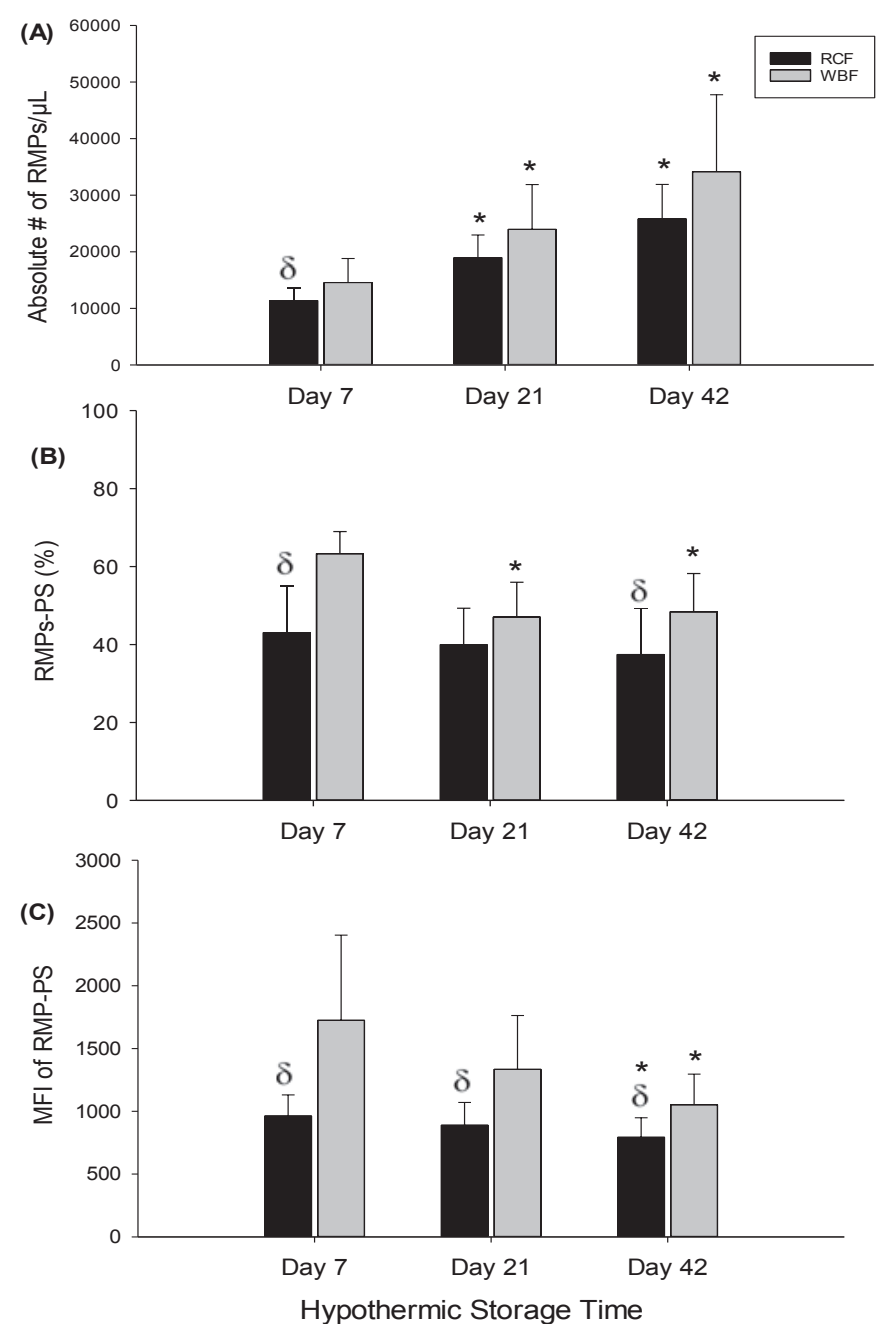

Fig. 1. Flow cytometer results shown the absolute number of $\mathrm{CD} 235+$ microparticles/ $\mu \mathrm{l}(\mathbf{A})$, the percent RMP-PS (B), and MFI of PS (C) on RMPs in stored RCC products (RCF and WBF). Data are reported as mean $\pm 1 \mathrm{SD}$. ${ }^{*} \mathrm{Sig}-$ nificant results $(\mathrm{p}<0.05)$ in comparison to day-7 values. $(\delta)$ Significant results $(\mathrm{p}<0.05)$ in comparison to WBF method.

Noteworthy, throughout hypothermic storage, MFIs of RMPs expressing PS in RCF samples was significantly lower than in WBF samples ( $\mathrm{p}<0.001$, fig. $1 \mathrm{C})$.

\section{TRPS: EVs in Stored RCCs Differ Between the Blood Processing Methods}

The TRPS analysis showed that heterogeneous submicron-sized vesicles are present in RCC products and accumulate during storage (fig. 2, 3). Although the total concentration of EVs/ml increased significantly during storage in RCF and WBF units, RCCs produced by WBF contained greater numbers of EVs in comparison to RCF (fig. $3 \mathrm{C}$ ). EVs in the stored RCC products were further categorized based on their size as either small EVs (EVs $<200 \mathrm{~nm}$ ) or large EVs $(E V s \geq 200 \mathrm{~nm})$. This characterization shows that the concentration of small EVs was higher in WBF units in comparison to the 

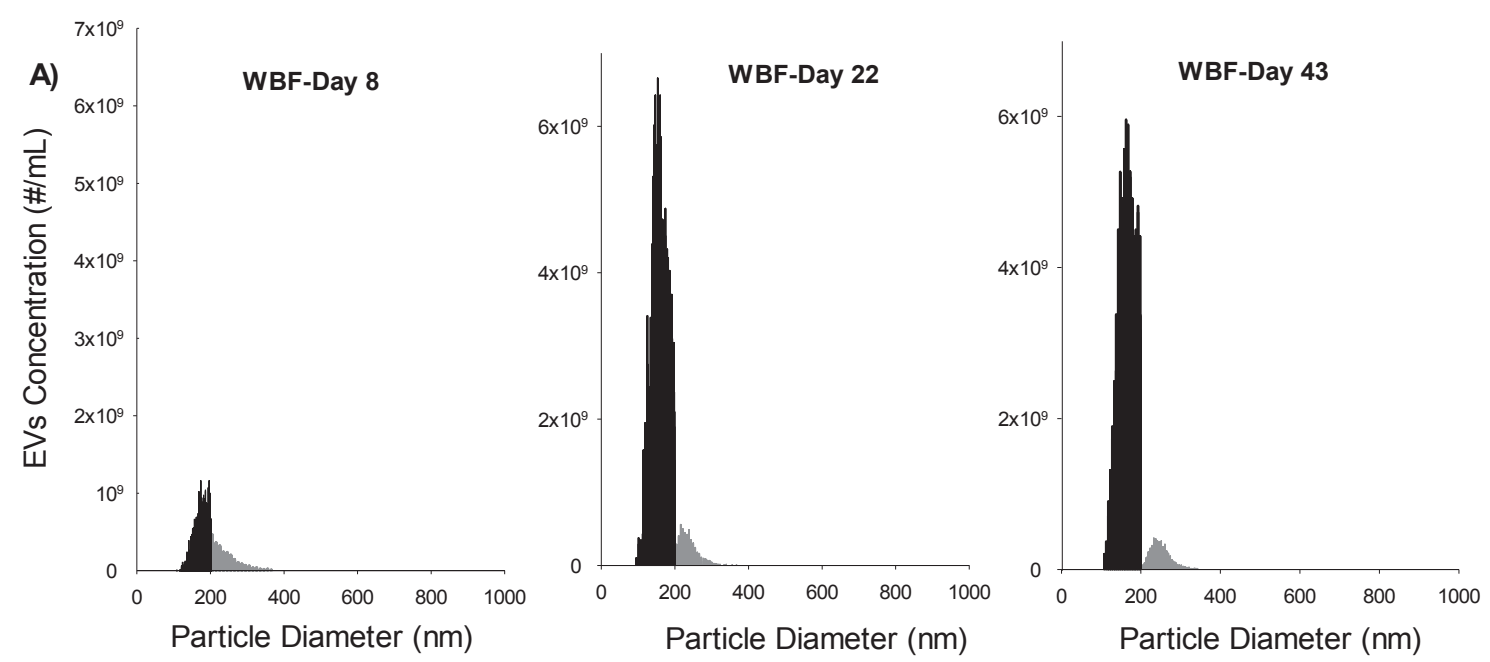

Fig. 2. Representative concentration $(\# / \mathrm{ml})$ versus size $(\mathrm{nm})$ histograms of extracellular vesicles in hypothermically stored RCCs (A WBF and B RCF) up to 43 days as meas-

ured by the TRPS
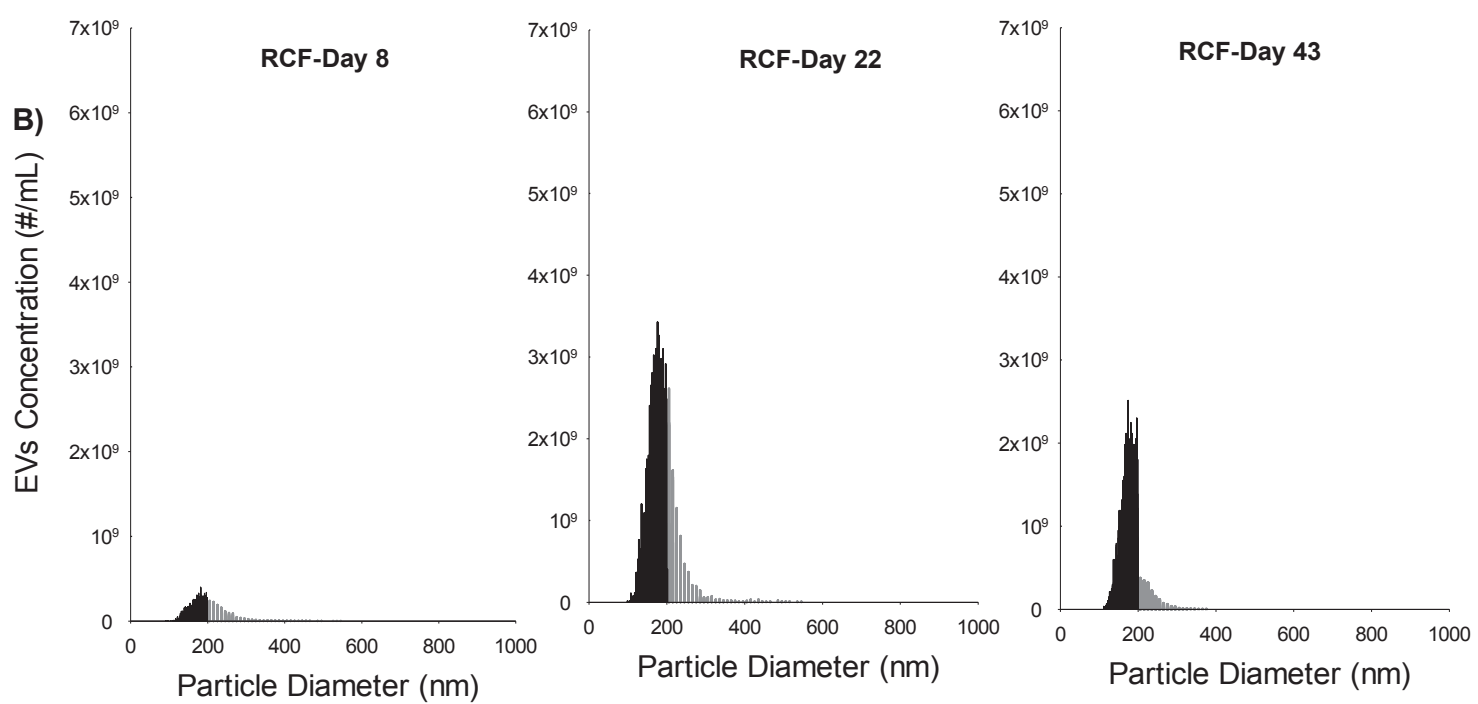

Table 1. Modal size of EVs from qNano measurements (mean \pm SD)

\begin{tabular}{lccc}
\hline Methods & Day 8 & Day 22 & Day 43 \\
\hline RCF method & & \\
EVs $<200 \mathrm{~nm}$ & $180 \pm 7.2$ & $186 \pm 6.0^{\dagger}$ & $187 \pm 6.7^{\dagger *}$ \\
EVs $\geq 200 \mathrm{~nm}$ & $211 \pm 15.8$ & $205 \pm 1.4^{\dagger}$ & $208 \pm 3.4^{\dagger}$ \\
\hline WBF method & & \\
EVs $<200 \mathrm{~nm}$ & $177 \pm 7.9$ & $168 \pm 12.5$ & $168 \pm 6.6$ \\
EVs $\geq 200 \mathrm{~nm}$ & $214 \pm 11.5$ & $219 \pm 5.7$ & $218 \pm 6.2$ \\
\hline *Significant results $(\mathrm{p}<0.05)$ in comparison to day 8 values. \\
${ }^{\dagger}$ Significant results $(\mathrm{p}<0.05)$ in comparison to WBF method. \\
\hline
\end{tabular}

RCF units (fig. 3A), and a significant difference between the two methods was observed again on day 43 of storage ( $p=0.0015$, fig. 3A). Statistically significant differences between the blood processing methods in the number of EVs/RMPs $\geq 200 \mathrm{~nm}$ were iden- tified only on day 22 of storage ( $p=0.0017$, fig. 3B). In addition, EV size profiling showed significant differences between RCF and WBF products on day 22 and 43 of storage $(\mathrm{p}<0.01$, table 1$)$.

\section{RBC in Vitro Quality Parameters Are Affected by Blood Manufacturing Methods and Storage Time}

Significant differences were observed between RCF and WBF methods in the level of ATP at the end of hypothermic storage time (day 42; $\mathrm{p}=0.0102$, table 2 ). In addition, there was a statistically significant decrease in the levels of ATP and 2,3-DPG on day 42 of storage compared to day 7 ( $\mathrm{p}<0.001)$.

In both RCF and WBF manufacturing methods, MCV slightly increased while MCHC significantly decreased throughout storage $(\mathrm{p}<0.001$, table 2$)$. Furthermore, the MCHC was significantly higher when using the WBF method in comparison to the RCF 

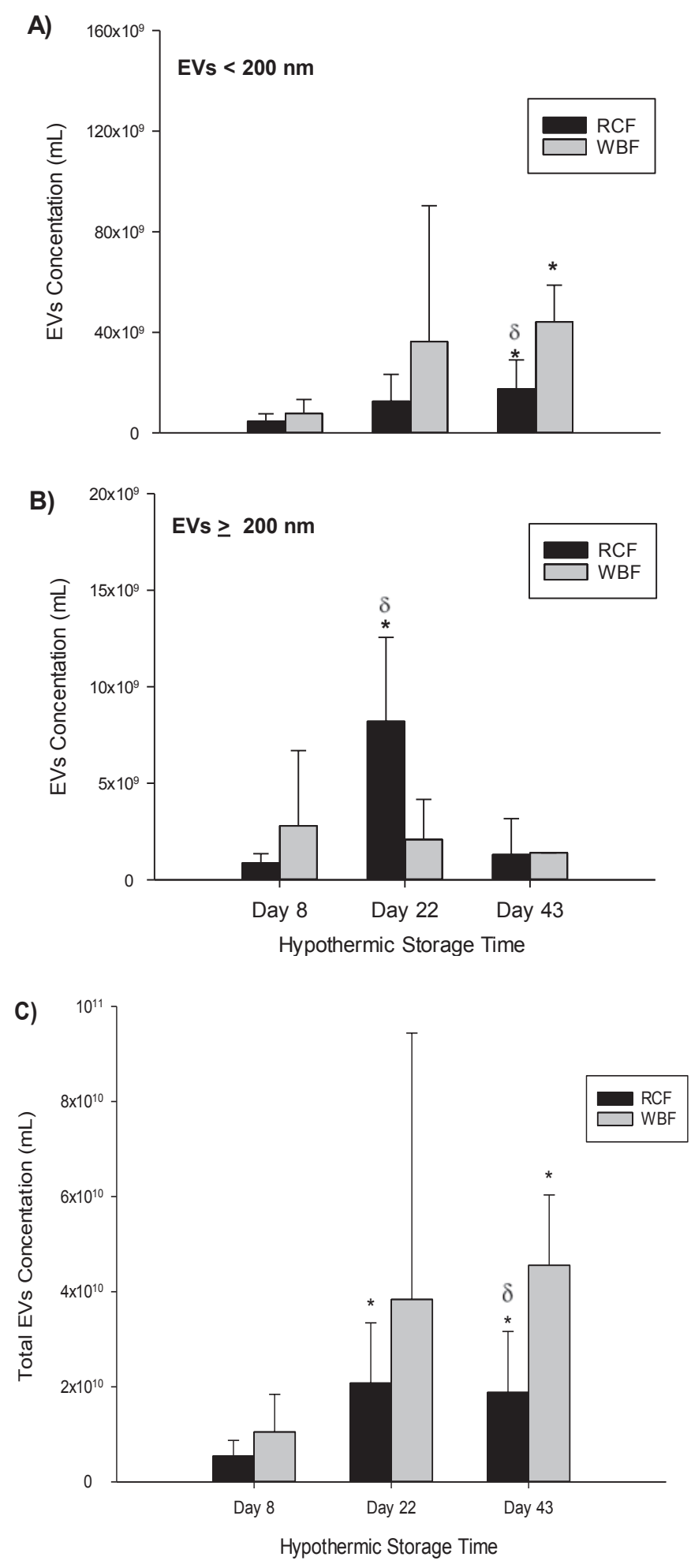

Fig. 3. Concentration of $E V s / m l$ in RCC products stored for up to 43 days analyzed by the TRPS system; A EVs $<200 \mathrm{~nm}$ using NP200, B EVs $\geq 200 \mathrm{~nm}$ using NP400, and $\mathbf{C}$ total EVs using NP200 and NP400. Data are reported as mean \pm SD. Significant results $(\mathrm{p}<0.05)$ in comparison to day- 8 values $\left({ }^{*}\right)$ or in comparison to $\mathrm{B} 2$ method $(\delta)$.

method early in the storage $(\mathrm{p}=0.0162)$ and at expiry $(\mathrm{p}=0.0496)$. However, there was no significant change detected in $\mathrm{MCH}$ during storage or between processing methods.
There was a significant increase in percent hemolysis during storage in both RCC products (RCF and WBF; $\mathrm{p}<0.001$, table 2). Notably, on day 42 , the WBF method showed greater percent hemolysis in comparison to the RCF method ( $p=0.005)$. Nevertheless, all samples fell within the acceptable level of hemolysis (less than $0.8 \%$ ) according to the Canadian Standards Association [46, 47].

RBC deformability measurements showed slight but statistically significant differences throughout storage in RCF and WBF units (table 2). $\mathrm{El}_{\max }$, which is a measure maximum elongation index of RBCs, decreased significantly at day 42 in comparison to day 7 of storage in RCF $(\mathrm{p}<0.001)$ and WBF method $(\mathrm{p}=0.039)$. Although RCCs produced by the RCF method were associated with lower $\mathrm{El}_{\max }$ at expiry $(0.50 \pm 0.01)$ in comparison to WBF units $(0.52 \pm$ 0.02 ), no statistically significant differences were identified between the two groups $(p=0.095)$. In addition, there were no significant difference in $\mathrm{K}_{\mathrm{EL}}$, which is a measure of $\mathrm{RBC}$ rigidity, between the two processing methods at early storage $(p=0.452)$ or at expiry $(\mathrm{p}=0.215)$.

The relationships between the microvesiculation and in vitro quality parameters throughout the hypothermic storage period were further investigated for both RCF and WBF RCCs (fig. 4). Moderate negative correlations were identified between the number of EVs and the level of ATP in both manufacturing methods (RCF: $\mathrm{R}^{2}=0.562$, WBF: $\mathrm{R}^{2}=0.562$ ) (fig. 4A). Additionally, while less strong negative correlations were observed between total number of EVs and $\mathrm{EI}_{\max }$ with RCF units $\left(\mathrm{R}^{2}=0.456\right)$, even weaker correlations were identified with WBF units $\left(\mathrm{R}^{2}=0.346\right)$ (fig. $\left.4 \mathrm{~B}\right)$. Correlation analysis also showed a moderately positive relationship between EV concentration and percent hemolysis in both processing methods (RCF: $\mathrm{R}^{2}=0.443, \mathrm{WBF}: \mathrm{R}^{2}=0.478$ ) (fig. $4 \mathrm{C}$ ).

\section{Discussion}

Although regulatory standards are applied for the processing and storage of RCCs to ensure the safety of the blood products, a number of product quality characteristics have been shown to be impacted by the manufacturing method and hypothermic storage $[3,22,31,48]$. Currently, the role that the storage duration may play on the quality of blood products and transfusion outcomes has been the focus of several studies $[22,35]$. Variability exists within the blood products themselves $[48,49]$, which may contribute to the storage lesions and adverse clinical outcomes. The blood component manufacturing processes and donor characteristics have emerged as major elements to explain some of the variability and conflicting clinical observations detected amongst blood products $[22,48,50]$. Here, we contribute to the current understanding on the impact of blood manufacturing methods and hypothermic storage duration on the characteristics of different subpopulations of EVs and in vitro quality parameters of RCCs produced by RCF and WBF processing methods. Significant differences in EV subpopulations and concentrations as well as cellular quality parameters were observed amongst RCC products throughout storage time. 
Table 2. Hemorheology and metabolism parameters for RCCs stored for up to 42 days $\left(\right.$ mean \pm SD) ${ }^{\mathrm{a}}$

\begin{tabular}{|c|c|c|c|c|}
\hline \multirow[t]{2}{*}{ Methods } & \multicolumn{2}{|c|}{ RCF (top/bottom) } & \multicolumn{2}{|l|}{ WBF (top/top) } \\
\hline & fresh & expired & fresh & expired \\
\hline \multicolumn{5}{|l|}{ Hematologic indices } \\
\hline $\mathrm{MCV}, \mathrm{fl}$ & $93.16 \pm 4.15$ & $96.93 \pm 4.04$ & $91.89 \pm 3.95$ & $94.78 \pm 4.18$ \\
\hline $\mathrm{MCH}, \mathrm{pg}$ & $29.73 \pm 1.57$ & $29.55 \pm 1.15$ & $29.98 \pm 1.43$ & $29.34 \pm 1.33$ \\
\hline $\mathrm{MCHC}, \mathrm{g} / \mathrm{l}$ & $319.08 \pm 6.20^{\dagger}$ & $304.83 \pm 5.34^{* \dagger}$ & $326.42 \pm 7.54$ & $309.67 \pm 6.04^{*}$ \\
\hline \multicolumn{5}{|l|}{ Deformability } \\
\hline Elmax & $0.53 \pm 0.01$ & $0.50 \pm 0.01^{*}$ & $0.53 \pm 0.01$ & $0.52 \pm 0.02^{*}$ \\
\hline $\mathrm{KEl}$ & $1.43 \pm 0.13$ & $1.41 \pm 0.18$ & $1.52 \pm 0.26$ & $1.56 \pm 0.31$ \\
\hline Hemolysis, \% & $0.09 \pm 0.02$ & $0.22 \pm 0.05^{\star} \dagger$ & $0.13 \pm 0.06$ & $0.35 \pm 0.15^{*}$ \\
\hline \multicolumn{5}{|l|}{ Metabolism } \\
\hline ATP, $\mu \mathrm{mol} / \mathrm{g} \mathrm{Hgb}$ & $4.25 \pm 0.63$ & $2.42 \pm 0.64^{*} \dagger$ & $3.90 \pm 0.62$ & $1.79 \pm 0.44^{*}$ \\
\hline 2,3 DPG, $\mu \mathrm{mol} / \mathrm{g} \mathrm{Hgb}$ & $5.10 \pm 2.98$ & $0.00^{*}(\mathrm{BDL})$ & $5.49 \pm 2.10$ & $0.00 *(\mathrm{BDL})$ \\
\hline \multicolumn{5}{|c|}{$\begin{array}{l}\mathrm{BDL}=\text { Below detection limit. } \\
{ }^{\mathrm{a} D a t a} \text { are reported as mean } \pm \text { SD. } \\
{ }^{\star} \text { Significant results }(\mathrm{p}<0.05) \text { in comparison to day } 7 \text { values. } \\
{ }^{\dagger} \text { Significant results }(\mathrm{p}<0.05) \text { in comparison to WBF method. }\end{array}$} \\
\hline
\end{tabular}

Data from TRPS showed that the total number of EVs increases significantly during hypothermic storage in both methods ( $\mathrm{p}<$ 0.05) and WBF contained the higher numbers of EVs in comparison to RCF which is consistent with other studies by our group [19, $22,31]$. It has been suggested that the characteristics of EVs can vary among the blood products due to the variation in the blood processing methods [51, 52]. An article by Bakkour et al. [19] highlighted some feasible reasons to explain the variation in EV characteristics between RCF and WBF RCCs, including variability in the temperature and the lengths of pre-processing storage time as well as leukoreduction technique. For instance, in WBF RCCs, filtration occurs before centrifugation and component separation while in RCF RCCs, leukoreduction occurs after these processes. Taking into account that leukoreduction removes not only leukocytes but also platelets and platelet-derived EVs from RCCs [53], and the buffy-coat removal improves the efficacy of pre-storage leukoreduction [54], it would be logical to predict that the lower EV count in RCF RCCs in comparison to WBF RCCs (fig. 1) may be, at least, due to the leukoreduction process. This is consistent with recent reports showing that RCF units have lower concentrations of platelet EVs and white blood cell (WBC) EVs when compared with other blood manufacturing methods, including the WBF method $[19,55]$. This also can explain our novel data captured by the TRPS which showed that the concentration of small EVs / exosomes $(<200 \mathrm{~nm})$ was greater in WBF units in comparison to RCF units with significant differences between the two methods on day 43 of storage ( $p=0.001$ ). It has been previously shown that RCF RCCs contain fewer residual cells (platelets and WBCs) in comparison to WBF RCCs as the RCF method removes the majority of the undesirable cells during the preparation of the buffy coat and before the leukoreduction [19]. In view of that, it is also more likely that WBF RCCs contain a larger number of small EVs such as platelet-derived EVs and WBC-derived EVs in comparison to RCF RCCs. However, it is important to mention that identifying the cell of ori- gin of these small EVs $(<200 \mathrm{~nm})$ detected in this study is yet to be elucidated, especially when considering the fact that most of the studies investigating EVs in RCC products account only for the microparticles that are characterized by the flow cytometer which lacks the ability to resolve the small EVs. Recently, great attention has been directed to the role of the 'contaminating' residual cells in RCCs, but the role of the EVs derived from these residual cells, which likely play the same role as their cell of origin, is still narrowly considered. Therefore, further studies are required to investigate the cell of origin of these EVs, particularly of the small EVs, and their potential influence on the quality of the products as well as their immunomodulatory effects after transfusion.

In addition to the EV data from TRPS, FC analysis showed that the concentration of CD235+ RBC-derived MPs significantly increased during the storage period in both manufacturing methods. It has been indicated that $\mathrm{RBC}$ membrane changes occur ex vivo and that there is a reduction in ATP and an increase in percent hemolysis, which are clearly associated with RBC membrane changes and microvesiculation [31, 51, 56-58]. This supports our findings that a positive correlation between EVs and hemolysis and a negative correlation between EVs and the level of ATP or deformability parameters $\left(\mathrm{El}_{\max }\right)$ were observed. Therefore, we hypothesize that the EV profile differences detected in the first week of storage are likely to be attributed to the cellular lesions induced by the variation in the blood processing methods, while the differences observed after the first week, toward the end of storage, are more likely reflecting the storage-related impacts [22].

In this study, assessing the RBC metabolism including ATP and 2,3-DPG showed significant depletion of these key metabolites by the end of storage (table 1). Depletion of ATP has been correlated with the in vivo survival of RBCs after transfusion, and the loss of 2,3-DPG from RBCs can impair oxygen transporting capacity [59]. Notably, ATP concentrations was significantly lower in the WBF $(1.79 \pm 0.44)$ when compared to RCF units $(2.42 \pm 0.64)$ on day 42 

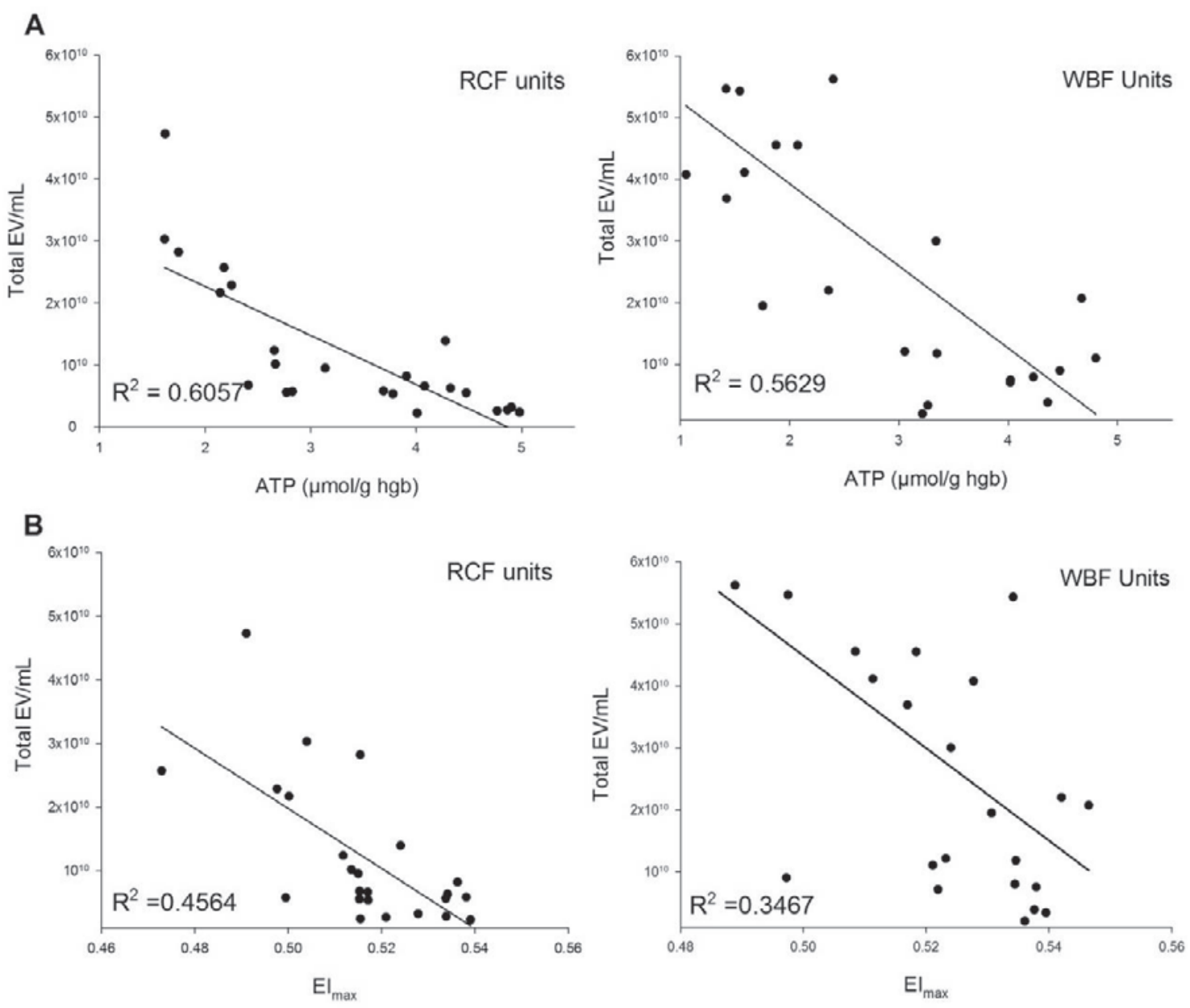

Fig. 4. Relationship between the total concentrations of EVs (EVs/ml) using TRPS and; (A), ATP, (B) Elmax, (C) \% hemolysis of stored RCCs (RCF and WBF method).
C

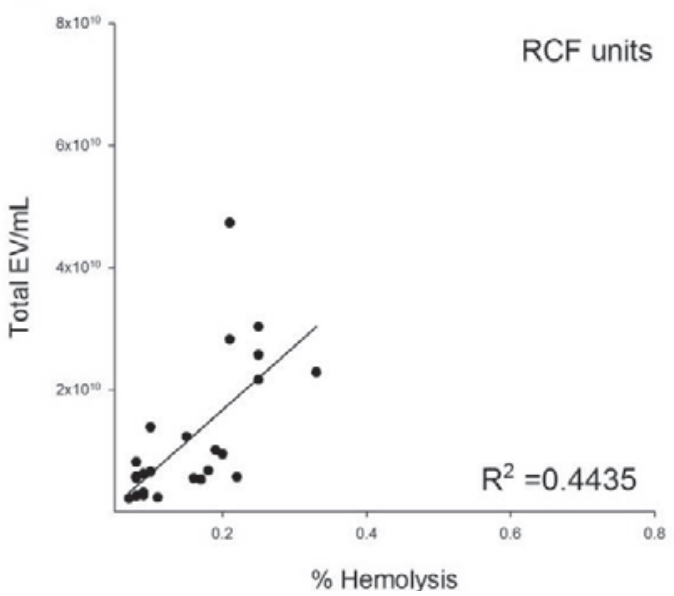

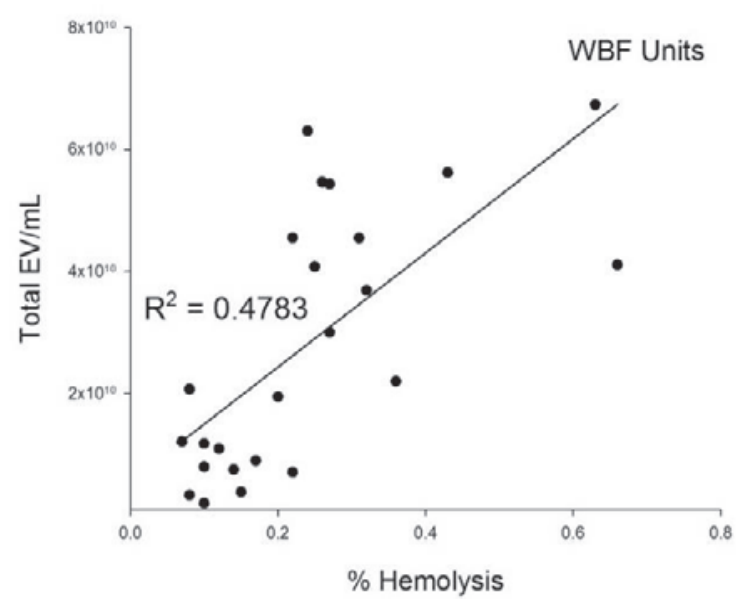

of storage. The level of ATP in the majority of WBF RCCs fell below the minimum recommended range of 2.3-2.7 $\mu \mathrm{mol} / \mathrm{g} \mathrm{Hb}$, which has been shown to correlate with $75 \%$ survival of transfused RBCs $24 \mathrm{~h}$ after transfusion [60]. However, as has been shown recently in metabolomics, lipidomic and proteomic studies, the hypothermic storage lesion involves many more changes to RBC metabolism than simply depletion of ATP and 2,3 DPG. Further studies are required to investigate the clinical impact of metabolic changes to stored RCCs.
Additionally, WBF RCCs showed stronger correlation between EVs and percent hemolysis throughout hypothermic storage in comparison to RCF RCCs. Furthermore, flow cytometric data also revealed that the RMPs and the percent of these RMPs expressing PS, a procoagulant factor, were significantly lower in RCF in comparison to WBF RCCs. Increasing the number of RMPs, which contain $\mathrm{Hb}$ and expressing PS, along with free $\mathrm{Hb}$ from hemolysis, are more likely to influence recipient immune response after transfusion [22]. For example, it has been shown that RMPs containing 
$\mathrm{Hb}$ have the ability to scavenge nitric oxide with the potential of reducing its bioavailability in post-transfusion state, resulting in impaired vascular function [61]. Moreover, Camus and his group [62] revealed that the RMPs carrying heme are cytotoxic as they can induce oxidative stress and apoptosis by activating the production of the endothelial reactive oxygen species. Noteworthy, a recent study by Danesh et al. [63] showed that the EV concentration in stored leukoreduced RCCs was largely due to the increase in both CD235+ RBC-derived EVs and CD41a+ platelet-derived EVs. They also demonstrated that leukoreduced RCCs contain small EVs / exosomes that are positive for CD63, and these exosomes have the capability to induce TNF-a secretion in monocytes. However, the accurate size, concentration, and phenotype of these exosomes were not revealed. The results of this study highlight the differences between differently manufactured RCC products in term of the size and concentration of EVs, especially of small EVs. However, the differences in the final manufactured products may not only influence the quality of the blood products but also patients' clinical outcomes [6]. Therefore, more studies are required to examine the potential adverse clinical outcomes of the EVs found within RCCs produced by different manufacturing methods in order to provide better blood products in clinical care. However, it is important to mention that it is not yet clear whether these findings and differences observed are due to the differences in manufacturing methods or due to other variables such as donor characteristics. Although donor factors such as sex and age may influence RCC products during storage [48], the main focus of this project was to understand how the quality of RCC products was affected by the manufacturing process chosen and storage duration. Further comprehensive studies are needed to understand the role of donor factors, storage duration, and blood manufacturing processes on patient outcomes.

\section{Conclusion}

In the present study we show that heterogeneous submicronsized vesicles are present in RCC products and that the frequency of the diverse populations of EVs is dependent on the blood manufacturing method. RCCs produced by WBF contained greater numbers of EVs in comparison to RCF units, particularly due to the higher concentration of small EVs / exosomes in WBF RCCs. This study also showed that the size profile and concentration of EVs is in a dynamic state of change throughout the hypothermic storage of RCCs. Differences in the final manufactured products may not only influence the quality of the blood products but also may affect patients' clinical outcomes. Therefore, further investigations to improve our understanding of the factors or processes that might be causing the variation amongst blood products is warranted in order to develop better strategies to minimize the risk associated with the transfusion of RCCs produced by different blood manufacturing methods, and to ensure that better-quality products are provided to patients.

\section{Acknowledgments}

The authors acknowledge Anita Howell (Centre for Innovation, Canadian Blood Services) for her contribution to project planning, coordination and testing. Authors also would like to thank Tracey Turner, Angela Hill, and April Xu (Centre for Innovation, Canadian Blood Services) for their technical support. The generous donation of all of our blood donors is gratefully acknowledged. We would also like to thank Bernice Asiedu-Ampem (production supervisor at Canadian Blood Services) for detailing the process of blood manufacturing methods. Ruqayyah Almizraq is supported by the Saudi Arabian Cultural Bureau in Canada as a recipient of a scholarship from the Government of Saudi Arabia. This work was funded by the Canadian Blood Services Intramural Grant program (grant number 2015IG-JA). Our research program received financial support from Canadian Blood Services, funded by the Federal (Health Canada), Provincial and Territorial Ministries of Health. The views expressed herein do not represent the views of the federal government.

\section{Disclosure Statement}

The authors have no conflicts of interest to disclose.

\section{References}

1 Ramirez-Arcos S, Marks DC, Acker JP, Sheffield WP Quality and safety of blood products. J Blood Transfus 2016;2016:2482157.

2 Tzounakas VL, Georgatzakou HT, Kriebardis AG, Voulgaridou AI, Stamoulis KE, Foudoulaki-Paparizos LE, Antonelou MH, Papassideri IS: Donor variation effect on red blood cell storage lesion: a multivariable, yet consistent, story. Transfusion 2016;56:1274-1286.

3 Jordan A, Chen D, Yi QL, Kanias T, Gladwin MT, Acker JP: Assessing the influence of component processing and donor characteristics on quality of red cell concentrates using quality control data. Vox Sang 2016;111:8-15.
Greenwalt TJ, Bryan DJ, Dumaswala UJ: Erythrocyte membrane vesiculation and changes in membrane composition during storage in citrate-phosphate-dextrose-adenine-1. Vox Sang 1984;47:261-270.

5 Dumaswala UJ, Dumaswala RU, Levin DS, Greenwalt TJ: Improved red blood cell preservation correlates with decreased loss of bands 3,4.1, acetylcholinestrase, and lipids in microvesicles. Blood 1996;87:1612-1616.

6 Acker JP, Hansen AL, Kurach JDR, Turner TR, Croteau I, Jenkins C: A quality monitoring program for red blood cell components: in vitro quality indicators before and after implementation of semiautomated processing. Transfusion 2014;54:2534-2543.
Mollison PL: The introduction of citrate as an anticoagulant for transfusion and of glucose as a red cell preservative. Br J Haematol 2000; 108:13-18.

${ }_{8}$ Bratosin D, Leszczynski S, Sartiaux C, Fontaine O, Descamps J, Huart JJ, Poplineau J, Goudaliez F, Aminoff D, Montreuil J: Improved storage of erythrocytes by prior leukodepletion: flow cytometric evaluation of stored erythrocytes. Cytometry 2001;46:351-356.

9 Wang D, Sun JF, Solomon SB, Klein HG, Natanson C: Transfusion of older stored blood and risk of death: a meta-analysis. Transfusion 2012;52:1184-1195.

10 Gladwin MT, Kanias T, Kim-Shapiro DB: Hemolysis and cell-free hemoglobin drive an intrinsic mechanism for human disease. J Clin Invest 2012;122:1205-1208. 
11 Hod EA, Spitalnik SL: Harmful effects of transfusion of older stored red blood cells: iron and inflammation. Transfusion 2011;51:881-885.

12 Hod EA, Spitalnik SL: Stored red blood cell transfusions: iron, inflammation, immunity, and infection. Transfus Clin Biol 2012;19:84-89.

13 Lannan KL, Sahler J, Spinelli SL, Phipps RP, Blumberg $\mathrm{N}$ : Transfusion immunomodulation - the case for leukoreduced and (perhaps) washed transfusions. Blood Cells Mol Dis 2013;50:61-68.

14 Refaai MA, Blumberg N: Transfusion immunomodulation from a clinical perspective: an update. Expert Rev Hematol 2013;6:653-663.

15 Scott KL, Lecak J, Acker JP: Biopreservation of red blood cells: past, present, and future. Transfus Med Rev 2005; 19:127-142.

16 Sparrow RL: Red blood cell storage and transfusionrelated immunomodulation. Blood Transfus 2010; 8(suppl 3):S26-S30.

17 Muszynski JA, Bale J, Nateri J, Nicol K, Wang Y, Wright V, Marsh CB, Gavrilin MA, Sarkar A, Wewers MD, Hall MW: Supernatants from stored red blood cell (RBC) units, but not RBC-derived microvesicles, suppress monocyte function in vitro. Transfusion 2015;55:1937-1945.

18 Heddle NM, Arnold DM, Acker JP, Liu Y, Barty RL, Eikelboom JW, Webert KE, Hsia CC, O’Brien SF, Cook RJ: Red blood cell processing methods and inhospital mortality: a transfusion registry cohort study. Lancet Haematol 2016;3:e246-254.

19 Bakkour S, Acker JP, Chafets DM, Inglis HC, Norris PJ, Lee TH, Busch MP: Manufacturing method affects mitochondrial DNA release and extracellular vesicle composition in stored red blood cells. Vox Sang 2016; 111:22-32.

20 Hogman CF: What quality of red blood cells shall we offer the transfused patient? ISBT Sci Ser 2006;1:120 126.

21 Radwanski K, Garraud O, Cognasse F, Hamzeh-Cognasse $\mathrm{H}$, Payrat J-M, Min K: The effects of red blood cell preparation method on in vitro markers of red blood cell aging and inflammatory response. Transfusion 2013;53:3128-3138.

22 Hansen AL, Kurach JD, Turner TR, Jenkins C, Busch MP, Norris PJ, Dugger J, Tomasulo PA, Devine DV, Acker JP: The effect of processing method on the in vitro characteristics of red blood cell products. Vox Sang 2015; 108:350-358

23 Spinella PC, Frazier E, Pidcoke HF, Dietzen DJ, Pati S, Gorkun O, Aden JK, Norris PJ, Cap AP: All plasma products are not created equal: characterizing differences between plasma products. J Trauma Acute Care Surg 2015;7(6 suppl 1):S18-25.

24 Muszynski JA, Spinella PC, Cholette JM, Acker JP, Hall MW, Juffermans NP, Kelly DP, Blumberg N, Nicol K, Liedel J, Doctor A, Remy KE, Tucci M, Lacroix J, Norris PJ, Pediatric Critical Care Blood Research Network (Blood Net): Transfusion-related immunomodulation: review of the literature and implications for pediatric critical illness. Transfusion 2017;57: 195-206.

25 Ley K, Laudanna C, Cybulsky MI, Nourshargh S: Getting to the site of inflammation: the leukocyte adhesion cascade updated. Nat Rev Immunol 2007;7:678-689.

26 Momen-Heravi F, Balaj L, Alian S, Mantel PY, Halleck AE, Trachtenberg AJ, Soria CE, Oquin S, Bonebreak CM, Saracoglu E, Skog J, Kuo WP: Current methods for the isolation of extracellular vesicles. Biol Chem 2013;394:1253-1262.

27 Yuana Y, Koning RI, Kuil ME, Rensen PC, Koster AJ, Bertina RM, Osanto S: Cryo-electron microscopy of extracellular vesicles in fresh plasma. J Extracell Vesicles 2013;2: doi 10.3402/jev.v2i0.21494.
28 Kastelowitz N, Yin H: Exosomes and microvesicles: identification and targeting by particle size and lipid chemical probes. Chembiochem 2014;15:923-928.

29 Van Der Pol E, Coumans F, Varga Z, Krumrey M, Nieuwland R: Innovation in detection of microparticles and exosomes. J Thromb Haemost 2013;11:36-45.

30 Haqqani AS, Delaney CE, Tremblay TL, Sodja C, Sandhu JK, Stanimirovic DB: Method for isolation and molecular characterization of extracellular microvesicles released from brain endothelial cells. Fluids Barriers CNS 2013;10:4.

31 Almizraq R, Tchir JDR, Holovati JL, Acker JP: Storage of red blood cells affects membrane composition, microvesiculation, and in vitro quality. Transfusion 2013; 53:2258-2267.

32 Lutz HU, Liu SC, Palek J: Release of spectrin-free vesicles from human erythrocytes during ATP depletion. I. Characterization of spectrin-free vesicles. J Cell Biol 1977;73:548-560.

33 Cardo LJ, Wilder D, Salata J: Neutrophil priming, caused by cell membranes and microvesicles in packed red blood cell units, is abrogated by leukocyte depletion at collection. Transfus Apher Sci 2008;38:117125.

34 Belizaire RM, Prakash PS, Richter JR, Robinson BR, Edwards MJ, Caldwell CC, Lentsch AB, Pritts TA: Microparticles from stored red blood cells activate neutrophils and cause lung injury after hemorrhage and resuscitation. J Am Coll Surg 2012;214:648-655.

35 Almizraq RJ, Seghatchian J, Acker JP: Extracellular vesicles in transfusion-related immunomodulation and the role of blood component manufacturing. Transfus Apher Sci 2016;55:281-291.

36 Straat M, Boing AN, Tuip-De Boer A, Nieuwland R, Juffermans NP: Extracellular vesicles from red blood cell products induce a strong pro-inflammatory host response, dependent on both numbers and storage duration. Transfus Med Hemother 2016;43:302-305.

37 Almizraq RJ, Seghatchian J, Holovati JL, Acker JP: Extracellular vesicle characteristics in stored red blood cell concentrates are influenced by the method of detection. Transfus Apher Sci 2017;56:254-260.

38 Headland SE, Jones HR, D'Sa ASV, Perretti M, Norling LV: Cutting-edge analysis of extracellular microparticles using ImageStream(X) imaging flow cytometry. Sci Rep 2014;4:5237.

39 Franquesa M, Hoogduijn MJ, Ripoll E, Luk F, Salih M, Betjes MG, Torras J, Baan CC, Grinyo JM, Merino AM: Update on controls for isolation and quantification methodology of extracellular vesicles derived from adipose tissue mesenchymal stem cells. Front Immunol 2014;5:525.

40 Levin E, Culibrk B, Gyöngyössy-Issa MIC, Weiss S, Scammell K, LeFresne W, Jenkins C, Devine DV: Implementation of buffy coat platelet component production: comparison to platelet-rich plasma platelet production. Transfusion 2008;48:2331-2337.

41 Hansen A, Yi Q-L, Acker JP: Quality of red blood cells washed using the ACP 215 cell processor: assessment of optimal pre- and postwash storage times and conditions. Transfusion 2013;53:1772-1779.

42 Drabkin DL: The standardization of hemoglobin measurement. Am J Med Sci 1949;217:710.

43 Sowemimo-Coker SO: Red blood cell hemolysis during processing. Transfus Med Rev 2002;16:46-60.

44 Stadnick H, Onell R, Acker JP, Holovati JL: Eadie-Hofstee analysis of red blood cell deformability. Clin Hemorheol Microcirc 2011;47:229-239.

45 Tchir JDR, Acker JP, Holovati JL: Rejuvenation of ATP during storage does not reverse effects of the hypothermic storage lesion. Transfusion 2013;53:3184-3191.

46 Canadian Standards Association: CAN/CSA_Z902-10 Blood and Blood Components. Ottawa, Canadian Standards Association, 2010.
Hess JR, Greenwalt TG: Storage of red blood cells: new approaches. Transfus Med Rev 2002;16:283-295.

48 Acker JP, Marks DC, Sheffield WP: Quality assessment of established and emerging blood components for transfusion. J Blood Transfus 2016;2016:4860284

49 van de Watering LMG: Age of blood: does older blood yield poorer outcomes? Curr Opin Hematol 2013;20: 526-532.

50 Hansen AL, Kurach JD, Turner TR, Jenkins C, Busch MP, Norris PJ, Dugger J, Tomasulo PA, Devine DV, Acker JP: The effect of processing method on the in vitro characteristics of red blood cell products. Vox Sang 2015; 108:350-358

51 Bicalho B, Pereira AS, Acker JP: Buffy coat (top/bottom)- and whole-blood filtration (top/top)-produced red cell concentrates differ in size of extracellular vesicles. Vox Sang 2015;109:214-220

52 Ryder AB, Zimring JC, Hendrickson JE: Factors influencing RBC alloimmunization: lessons learned from murine models. Transfus Med Hemother 2014;41: 406-419.

53 Sugawara A, Nollet KE, Yajima K, Saito S, Ohto H: Preventing platelet-derived microparticle formationand possible side effects-with prestorage leukofiltration of whole blood. Arch Pathol Lab Med 2010;134: 771-775.

54 Sonker A, Dubey A, Chaudhary R: Evaluation of a red cell leukofilter performance and effect of buffy coat removal on filtration efficiency and post filtration storage. Indian J Hematol Blood Transfus 2014;30:321-327.

55 Almizraq RJ, Inglis H, Norris PJ, Muszynski JA, Juffermans NP, Holovati JL, Acker JP: Characteristics of extracellular vesicles in stored red blood cell products influenced by component manufacturing method. Transfusion 2017;57:81A (abstract).

56 Greenwalt TJ: The how and why of exocytic vesicles. Transfusion 2006;46:143-152.

57 Holovati JL, Wong KA, Webster JM, Acker JP: The effects of cryopreservation on red blood cell microvesiculation, phosphatidylserine externalization, and CD47 expression. Transfusion 2008;48:1658-1668.

58 Orbach A, Zelig O, Yedgar S, Barshtein G: Biophysical and biochemical markers of red blood cell fragility. Transfus Med Hemother 2017;44:183-187.

59 de Korte S, Verhoeven AJ: Quality determinants of erythrocyte destined for transfusion. Cell Mol Biol 2004;50:187-196.

60 van der Meer PF, Pietersz RN: Overnight storage of whole blood: a comparison of two designs of butane-1,4-diol cooling plates. Transfusion 2007; 47: 2038-2043.

61 Donadee C, Raat NJH, Kanias T, Tejero J, Lee JS, Kelley EE, Zhao XJ, Liu C, Reynolds H, Azarov I, Frizzell S, Meyer EM, Donnenberg AD, Qu LR, Triulzi D, Kim-Shapiro DB, Gladwin MT: Nitric oxide scavenging by red blood cell microparticles and cell-free hemoglobin as a mechanism for the red cell storage lesion. Circulation 2011;124:465-476.

62 Camus SM, De Moraes JA, Bonnin P, Abbyad P, Le Jeune S, Lionnet F, Loufrani L, Grimaud L, Lambry JC Charue D, Kiger L, Renard JM, Larroque C, Le Clesiau $\mathrm{H}$, Tedgui A, Bruneval P, Barja-Fidalgo C, Alexandrou A, Tharaux PL, Boulanger CM, Blanc-Brude OP: Circulating cell membrane microparticles transfer heme to endothelial cells and trigger vasoocclusions in sickle cell disease. Blood 2015;125:3805-3814.

63 Danesh A, Inglis HC, Jackman RP, Wu SQ, Deng XT, Muench MO, Heitman JW, Norris PJ: Exosomes from red blood cell units bind to monocytes and induce proinflammatory cytokines, boosting T-cell responses in vitro. Blood 2014;123:687-696 